\title{
Longitarsus ozbeki sp. n., a new species from Asia Minor (Coleoptera: Chrysomelidae: Alticinae)
}

\author{
Ifran Aslan \& Andrzej Warchalowski
}

Aslan, I. \& Warchalowski, A. 2005: Longitarsus ozbeki sp. n., a new species from Asia Minor (Coleoptera: Chrysomelidae: Alticinae). — Entomol. Fennica 16: $221-224$.

A series of ca. 50 specimens of a small Longitarsus Latr. in the undescribed species were collected from the North-East of Asia Minor in the field research during the 21.VIII-1.IX.2003. Longitarsus ozbeki sp. n. is described and illustrated from north west of Turkey. This species is phenotypically similar to Longitarsus albineus (Foudras) and Longitarsus artvinus Gruev \& Aslan. L. ozbeki sp. n. differs from the other two species by the outline of pronotum, coloration of body, punctuation of elytra, coloration of claws, tarsomeres, and metanotum, central lobe of anal sternite in male, aedeagus and spermathecae. Length of body is 1.9$2.2 \mathrm{~mm}$ (mean $2.13 \mathrm{~mm}$ ) and 2.4-2.6 $\mathrm{mm}$ (mean $2.46 \mathrm{~mm}$ ) in male and female, respectively.

I Aslan, Atatürk University, Agricultural Faculty, Plant Production Department, 25240 Erzurum,Turkey; E-mail: iaslan@atauni.edu.tr, aslanir@hotmail.com A. Warchalowski, Zoological Instute, University of Wroclaw, Sienkiewicza 21, 50-335 Wroclaw, Poland

Received 12 October 2004, accepted 24 March 2005

\section{Introduction}

The Alticinae or flea beetles are the most diverse subfamily of leaf beetles (Coleoptera: Chrysomelidae). They are distributed worldwide, but the majority of genera and species occur in the tropical region of South America, Africa and Asia. The Palaearctic fauna is relatively poor, with 59 genera and ca. 1,000 species (Lopatin 1977, Konstantinov \& Vandenberg 1996, Aslan et al. 1999). Many alticines are known as economic pests that cause direct damage by feeding on wide range of different plant species and, especially adults, transmitting viruses. However, several species, including Longitarsus, Altica, Aphthona and Pseudolapmsis, have been successfully used in the biological control of weeds (Aslan et al. 2003).
The genus of Longitarsus is the largest genus of Alticinae with more than 250 Palaearctic species and about 500 species worldwide (Kostantinow \& Vandenberg 1996). It has 46 species in Central Asia and Kazakhstan (Lopatin 1977) and 163 species in Europe and Mediterranean area (Warchalowski 1996, 2003). A total of 72 Longitarsus species are currently known from Turkey (Aslan et al. 1999, 2002, 2004, Aslan \& Warchalowski 2001). In Longitarsus, body is small to medium-sized, oval, more or less convex, yellow, brown or black with or without metallic luster. Elytral suture is usually dark, and elytra rarely with spot at middle or at apex. Apical $2 / 3$ of metatibia is flat. Apical part is thickened and apical spine is usually large, inserted almost at middle. First metatarsal segment is very long, not shorter than $1 / 2$ of tibia. 
Although the distribution and taxonomy of Longitarsus species are well known, their host plants and life cycles have been less studied. Certain Longitarsus species have recently become important biological control agents of some weeds (Aslan \& Özbek 1999, Aslan et al. 2003). As more is learned about their host-plant relationships, other species are bound to gain importance in biological control. The species of Longitarsus are known to feed on Achilla, Alcanna, Anchusa, Artemisia, Asperugo, Ballota, Borago, Cerinthe, Cynoglossum, Echium, Lappula, Linum, Lithospermum, Lycopus, Majorana, Marrubium, Matricaria, Mentha, Myosotis, Plantago, Pulmonaria, Ranunculus, Salvia, Stachys, Symphytum, Tanacetum, Thalictrum and Tournefortia (Medvedev \& Roginskaya 1988).

This study describes Longitarsus ozbeki sp. n. from north-eastern Turkey.

\section{Material and Methods}

This study was based on biological material collected from the pass Kop Geçidi, $80 \mathrm{~km}$ West of Erzurum (2,330 m a.s.l.), Turkey, 21.VIII.1.IX.2003. Sampling was conducted throughout the growing seasons from the vegetation using a sweep net and a mouth aspirator. In identification, standard keys to Longitarsus were used (Lopatin 1977, Warchalowski 1996, 2003, Gruev \& Aslan 1998). Material belonging to genus Longitarsus was compared with the paratypes and holotypes in the different collections.

The examined material is deposited at the Atatürk University, Agricultural Faculty, Plant Protection Department, Erzurum 25240, Turkey (EMET) (Entomology Museum Erzurum Turkey) and A. Warchalowski's collection. In addition, some paratypes of these species have been sent to different European museums.

\section{Species description}

Longitarsus ozbeki Aslan \& Warchałowski, sp. n.

Diagnosis. Ocular furrows distinct, frontal calli absent. Spur of hind tibia short. Body length is below $2.6 \mathrm{~mm}$. Body, except eyes and the terminal half of antennae entirely pale yellowish. Hind wings and humeral calli well developed. Tubular part of aedeagus in lateral view straight, insertion of ducts spermathecae inclined to dorsal size of vasculum.

Description. Body very pale, yellowish and terminal half of antennae darkened, in mature specimens black. Labrum is usually brownish. Length of body in male is $1.9-2.2 \mathrm{~mm}$ (on average $2.13 \mathrm{~mm}$ ), in female $2.4-2.6 \mathrm{~mm}$ (on average $2.46 \mathrm{~mm}$ ). Antennae $0.7 \mathrm{X}$ (in female) to $0.8 \mathrm{X}$ (in male) as long as the body, antennomeres feebly differentiated, 2 and 3 shorter, while 5-7 longer than the remaining ones. Ocular furrows deep, frontal calli absent, otherwise head without particular characters. Pronotum 1.30-1.35 X broader than long, extremely finely and shallowly punctuated, ground almost smooth, with a greasy sheen. Elytra are finely and shallowly punctuate, humeral calli distinct. In male, fore metatarsus slightly broadened, anal sternite with a small and deep hollow on central lobe. Aedeagus (Fig. 1ab; total length $700-800 \mu \mathrm{m}$ ) relatively broad, semitransparent and very pale, which renders it more difficult to distinguish of structural details. Apical lamella weakly marked. Aedeagus of tubular part in lateral view is entirely straight (Fig. 1b). Spermatheca is as in Fig. 1c; ducts very pale, inserted semi-dorsally, and forms 1 or 2 incomplete loops.

Locus typicus. The pass Kop Geçidi, 80 km West of Erzurum, 2,330 m a.s.1.

Host plant. Unknown.

Type material. 18 specimens: holotype, allotype and 4 paratypes intended for the Naturhistorisches Museum, Basel, 13 paratypes (in good condition) intended: one pair for Muséum national d'Histoire naturelle, Paris, one pair for Museum für Naturkunde, Berlin. Further paratypes in private collections of M. Bergeal (Versailles), M. Döberl (Abensberg), U. Heinig (Berlin), C. Leonardi (Milano), G. Bastazo and J.-M. Vela (Cartaya), remaining paratypes deposited at the Atatürk University, Agricultural Faculty, Plant Protection Department (Entomology Museum, Erzurum) and in the collections of both authors.

Labelling of holotype: 1 [printed on white paper]: TURKEY (Erzurum), sella Kop Geçidi, 2,330 m, 28.VIII.2003, leg. A. Warchalowski; 2 


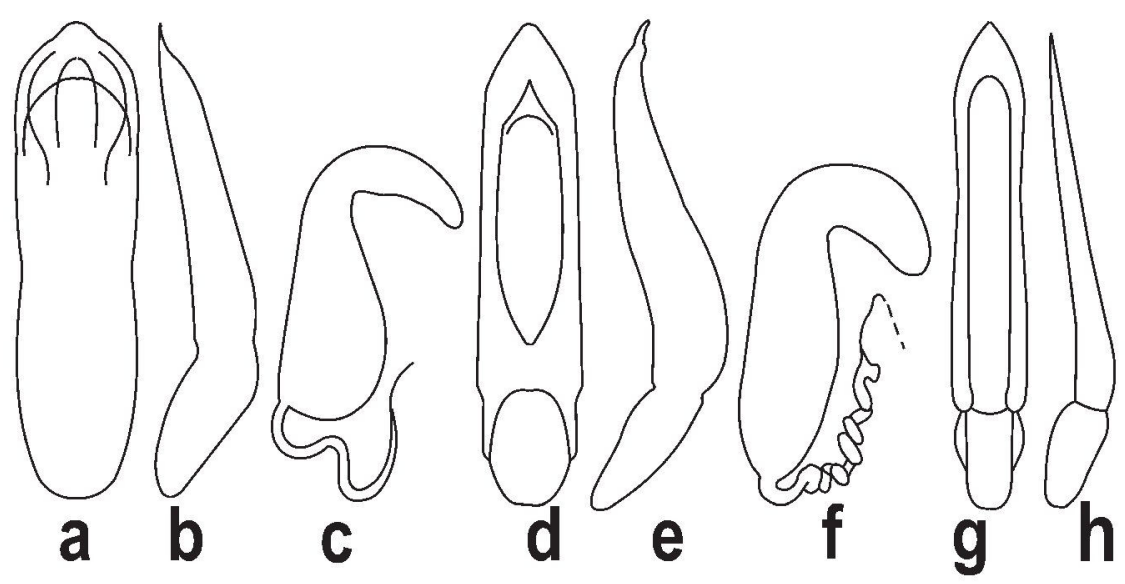

Fig. 1. - a. Longitarsus ozbeki sp. n.; aedeagus, dorsoventral view. - b. Longitarsus ozbeki, aedeagus, lateral view. - c. Longitarsus ozbeki, spermatheca. - d. L. albineus (Foudras); aedeagus, dorsoventral view. - e. L. albineus; aedeagus, lateral view. - f. $L$. albineus; spermatheca. - g. L. artvinus Gruev \& Aslan; aedeagus, dorsoventral view. - h. L. artvinus; aedeagus, lateral view. Original illustrations, except d-e (from Warchalowski 2003) and g-h (from Gruev \& Aslan 1998).

[printed on white paper]: Longitarsus ozbeki sp. n., det. A. Warchalowski; 3 [printed on red paper]: HOLOTYPE. Labelling of paratypes: 1. TURKEY (Erzurum), sella Kop Geçidi, 2,330 m, 28.VIII.2003, leg. A. Warchalowski [or I. Aslan]; 2 [Printed on white paper]: Longitarsus ozbeki Aslan et Warchalowski, det. A. Warchalowski [or Longitarsus ozbeki Warch., det. I. Aslan]; 3 [Printed on red paper]: PARATYPE.

Etymology. The species is dedicated to Dr. Hikmet Özbek, Professor of Entomology in Plant Protection Department, Agricultural Faculty, Atatürk University, Erzurum, Turkey.

\section{Key for similar species}

1. Outline of pronotum longer; in dorsal view at most $1.35 \mathrm{X}$ broader than long; punctuation of elytra very fine and shallow; coloration of claws and tarsomeres 3-4 pale, at most slightly darkened; coloration of metanotum always entirely pale; central lobe of anal sternite in male with small roundish hollow; apex of aedeagus with slightly marked lamella; apical borders of the aedeagus form an angle of more than $90^{\circ}$ (Fig. 1a); aedeagus in lateral view straight (Fig. 1b); insertion of ducts of spermathecae inclined to dorsal side of vasculum (Fig. 1c); number of ducts loops $1-2$

Longitarsus ozbeki sp. n.

- Outline of pronotum shorter; in dorsal view ca. 1.50-1.55 X broader than long; punctuation of elytra fine or moderately strong; central lobe of anal sternite in male with longitudinal impression; apex of aedeagus without lamella

2. Punctuation of elytra fine or moderately strong; coloration of metanotum at less distinctly darkened, usually with two black roundish spots (shining trough when elytra moistened by water or other solvent); coloration of claws and tarsomeres 3-4 pale, at most slightly darkened; apical borders of aedeagus form an angle of about $70^{\circ}$ (Fig. 1d); aedeagus in lateral view slightly but distinctly S-like bent (Fig. 1e); insertion of ducts spermathecae at bottom of vasculum (Fig. 1f); number of ducts loops 8-12

Longitarsus albineus (Foudras)

- Punctuation of elytra fine; coloration of metanotum pale; coloration of claws and tarsomeres 3-4 blackish-brown; apical borders of aedeagus form an angle of about $60^{\circ}$ (Fig. 1g); aedeagus in lateral view straight (Fig. 1h); spermathecae is unknown Longitarsus artvinus Gruev \& Aslan. 


\section{Discussion}

In the described $L$. ozbeki there is a striking contrast between the pale body and the dark apical part of antennae, similarly as in L. albineus (Foudras) and L. artvinus Gruev \& Aslan. All the remaining pale-coloured species are small WestPalaearctic species of Longitarsus with well-developed humeral calli, viz. L. caroli Bastazo \& Garcia Raso, L. celticus Leonardi, L. noricus Leonardi, L. pellucidus (Foudras), L. solaris Gruev \& Canarian and L. nubigena Wollaston, have entirely pale or apically insignificantly darkened antennae. Externally, L. ozbeki resembles only L. albineus (Foudras) and L. artvinus; the differences are presented in the key of the similar species (see above).

Acknowledgements. We would like to express our thanks to Dr. Beata Pokryszko (Wrocław) and Dr. K. Haliloglu (Erzurum) for the linguistic corrections.

\section{References}

Aslan, I \& Ozbek, H. 1999: Occurence of leaf-beetles (Coleoptera, Chrysomelidae) in the vicinity of Erzurum cause significant damage on weeds. - Proceedings of the Fourth Turkish National Congress of Entomology, 26-29 January 1999, Adana: 75-86. [In Turkish, with English summary.]

Aslan, I. \& Warchalowski, A. 2001: New records of the subfamily Alticinae (Coleoptera, Chrysomelidae) for the Turkish fauna. - J. Ent. Res. Soc. 3 (1-2): 1-4.

Aslan, I., Gruev, B. \& Ozbek, H. 1999: A Preliminary Review of the Subfamily Alticinae (Coleoptera, Chrysomelidae) in Turkey. - Tr. J. Zool. 3 (4): 373-414.

Aslan, I., Been, R. \& Ozbek, H. 2002: New records of leaf beetles from Turkey (Coleoptera, Chrysomelidae). Ent. B1. 98: 231-235.

Aslan I., Ozbek, H. \& Konstantinov, A. 2003: Flea beetles (Coleoptera, Chrysomelidae) occuring on Amaranthus retreflexus L. in Erzurum province, Turkey, and their potential as biological control agents. - Proc. Entomol. Soc. Wash. 105 (2): 441-446.

Aslan, I., Ozbek, H. \& Warchalowski, A. 2004: Five new records, new localities and new host plants for the Turkish flea-beetle fauna (Coleoptera: Chrysomelidae: Alticinae). - Entomol. Fennica 15: 138-141.

Gruev, B. \& Aslan, I. 1998: Four new species of the subfamily Alticinae (Coleoptera, Chrysomelidae) from Turkey. — Türk entomol. Derg. 22 (3): 163-169.

Konstantinov, A. S. \& Vandenberg, N. J. 1996: Handbook of Palearctic Flea Beetles (Coleoptera: Chrysomelidae: Alticinae). Vol. 1, Number 3, Associated Publishers, Gainesville, Florida. 439 pp.

Lopatin, I.K. 1977: Leaf-Beetles (Chrysomelidae) of Middle Asia and Kazakhstan. - Nauka. 289 pp.

Medvedev, L.M. and Roginskaya, E.Y. 1988: Catalog of the leafbeetles host plants of the USSR fauna. - Moscow. $191 \mathrm{pp}$.

Warchalowski, A. 1996: Übersicht der westpalaarktischen Arten der Gattung Longitarasus Berthold, 1827 (Coleoptera: Chrysomelidae: Alticinae). — Polish Taxonomical Society, BS, Wroclaw. 266 pp.

Warchalowski, A. 2003: Chrysomelidae, The Leaf-Beetles of Europe and the Mediterranean Area. - Natura Optima Dux Foundation Warszawa. 600 pp. 